\title{
BMI and obesity in US blood donors: a potential public health role for the blood centre
}

\author{
Edward L Murphy ${ }^{1,2, *}$, Karen Schlumpf ${ }^{3}$, David J Wright ${ }^{3}$, Ritchard Cable ${ }^{4}$, John \\ Roback ${ }^{5,6}$, Ronald Sacher ${ }^{7}$ and Michael P Busch ${ }^{2}$ for the NHLBI Retrovirus \\ Epidemiology Donor Study II \\ 'Laboratory Medicine and Epidemiology/Biostatistics, University of California San Francisco, San Francisco, \\ CA, USA: ${ }^{2}$ Blood Systems Research Institute, 270 Masonic Avenue, San Francisco, CA 941 18, USA: ${ }^{3}$ Westat \\ Inc., Rockville, MD, USA: ${ }^{4}$ American Red Cross Blood Services, New England Region, Farmington, CT, USA: \\ ${ }^{5}$ American Red Cross Blood Services, Southern Region, Atlanta, GA, USA: ${ }^{6}$ Emory University, Atlanta, GA, \\ USA: ${ }^{7}$ Hoxworth Blood Center, University of Cincinnati Medical Center, Cincinnati, OH, USA
}

Submitted 9 March 2011: Accepted 17 November 2011: First published online 10 January 2012

\begin{abstract}
Objective: According to the 2007-2008 National Health and Nutrition Examination Survey, the prevalence of obesity in the US population was $33 \cdot 8 \% ; 34 \cdot 3 \%$ and $38 \cdot 2 \%$, respectively, in middle-aged men and women. We asked whether available blood donor data could be used for obesity surveillance.

Design: Cross-sectional study of BMI and obesity, defined as BMI $\geq 30 \cdot 0 \mathrm{~kg} / \mathrm{m}^{2}$.

Adjusted odds ratios (aOR) were calculated with logistic regression.

Setting: A network of six US blood centres.

Subjects: Existing data on self-reported height and weight from blood donors, excluding persons deferred for very low body weight.

Results: Among 1042817 donors between January 2007 and December 2008, the prevalence of obesity was $25 \cdot 1 \% ; 25.7 \%$ in men and $24.4 \%$ in women. Obesity was associated with middle age (age 50-59 years $v$. $<20$ years: aOR $=1.92$ for men and 1.81 for women), black (aOR $=1.57$ for men and 2.35 for women) and Hispanic $(\mathrm{aOR}=1.47$ for men and 1.49 for women) race/ethnicity compared with white race/ethnicity, and inversely associated with higher educational attainment (college degree $v$. high school or lower: $\mathrm{aOR}=0.56$ for men and 0.48 for women) and double red cell donation and platelet donation.

Conclusions: Obesity is common among US blood donors, although of modestly lower prevalence than in the general population, and is associated with recognized demographic factors. Blood donors with higher BMI are specifically recruited for certain blood collection procedures. Blood centres can play a public health role in obesity surveillance and interventions.
\end{abstract}

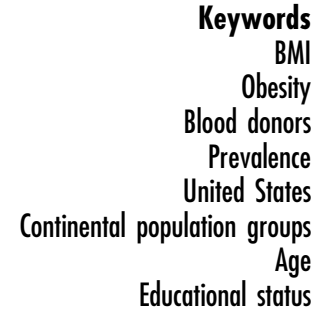

Obesity has been described as epidemic in the USA, with significant adverse consequences for the incidence of diabetes and CVD, premature mortality and reduced quality of life ${ }^{(1-3)}$. According to National Center for Health Statistics data from the National Health and Nutrition Examination Survey (NHANES) 2007-2008, obesity prevalence by age was: $27.5 \%$ in men and $34.0 \%$ in women for ages $20-39$ years; $34 \cdot 3 \%$ in men and $38 \cdot 2 \%$ in women for ages 40-59 years; and 37.1\% in men and 33.6\% in women for ages 60 years and above ${ }^{(4)}$. That study noted that the upward trend of obesity observed in the US population over the past 30 years may be levelling off in the decade since 1999-2000. The Centers for Disease Control and Prevention have also used self-reported height and weight data from the US Behavioral Risk
Factor Surveillance System (BRFSS) to estimate countylevel prevalence of obesity. Counties with the highest prevalence of obesity were concentrated in West Virginia, the Appalachian counties of Tennessee and Kentucky, much of the Mississippi Delta, and the southern belt extending across Louisiana, Mississippi, middle Alabama, south Georgia and the coastal regions of the Carolinas ${ }^{(5)}$. However the authors noted limitations of both national surveillance mechanisms, including small sample size in sex and age strata for NHANES and potential response bias in the BRFSS.

Despite a moderate degree of selection bias due to volunteer bias and health criteria, blood donors provide a potential population for the ongoing surveillance of obesity and other health-related risk factors. Certainly such data 
have been useful in surveillance for HIV and West Nile virus $^{(6,7)}$. Data on large numbers of individuals are available from across the USA, and data are available continuously as opposed to episodic surveys. We are not aware of published data on BMI distributions among blood donors. Such information may be useful for public health surveillance, and also because body mass criteria are used to define eligibility for certain types of blood collection (e.g. double red cell donation) and prevention of syncopal reactions.

We therefore used data from a large, multicentre consortium of US blood centres to perform a descriptive analysis of BMI. Although the prevalence of obesity was modestly lower among blood donors compared with the general US population, demographic and geographic differences were observed that may be useful to ongoing public health surveillance.

\section{Methods}

\section{Study population}

The Retrovirus Epidemiology in Donors Study II (REDS-II) is a multicentre consortium of six blood centres located across the USA (see Table 1 and Appendix) which share data on all blood donations at their centres in a centralized research database. We included data on all successful allogeneic blood donations from donors at the six REDS-II centres from January 2007 to December 2008. All donors were unremunerated volunteers. Autologous (those who donate for themselves) and therapeutic (those who are phlebotomized for medical indications) blood donations were excluded. Whole blood, double red cell and platelet apheresis donations were included. Donors who gave more than one donation during the study period contributed only one observation, namely data recorded at their first donation. Prospective blood donors weighing less than $110 \mathrm{lb}(50 \mathrm{~kg})$ are deferred from blood donation, as are donors under the age of 18 years who fail more stringent weight requirements and individuals with various medical or behavioural risks to safe blood donation, as reported previously ${ }^{(8-10)}$. Deferred donors were not included in the present study. Height and weight were self-reported by donors at the time of donation, and recorded by blood centre personnel on the blood donation record or a supplemental research form. Data collection was approved by the relevant institutional review boards at each blood centre and the coordinating centre.

\section{Statistical analyses}

BMI was calculated as weight (in kilograms) divided by the square of height (in metres). Density plots were constructed showing the proportion of the study population or subgroup with each integer value of BMI. Obesity was defined $^{(4)}$ as BMI $\geq 30 \cdot 0 \mathrm{~kg} / \mathrm{m}^{2}$, and overall and subgroup-specific prevalences of obesity were calculated. Crude obesity prevalences and empirical BMI values are presented in Table 1 and Figs 1 and 2. Obesity prevalence was standardized by sex, age and race/ethnicity to the year 2000 US census population using the direct method $^{(4)}$. Finally, adjusted odds ratios (aOR) for obesity and $95 \%$ confidence intervals were calculated using multivariable logistic regression. All of the variables shown in Table 1, including education as a surrogate for socioeconomic status, were included in the model. All data analyses and multivariable models were conducted using the SAS statistical software package version 9.1 (SAS Institute Inc., Cary, NC, USA).

\section{Results}

We analysed data on donors who gave any type of allogeneic donation between 1 January 2007 and 31 December 2008. During this time 331764 donors who were deferred from blood donation, including 2386 reports of low weight, were excluded from the analysis. A total of $38386(3.6 \%)$ allogeneic donors were excluded because of missing height and/or weight data, leaving 1042817 for whom complete BMI data were available and included in the present study. The overall BMI distributions for men and women showed the following proportions of donors in each BMI category: (i) for men, $30 \%$ were underweight/normal weight $\left(\mathrm{BMI} \leq 24 \cdot 9 \mathrm{~kg} / \mathrm{m}^{2}\right)$, $41 \%$ were overweight $\left(\mathrm{BMI}=25 \cdot 0-29 \cdot 9 \mathrm{~kg} / \mathrm{m}^{2}\right), 29 \%$ were obese (BMI $\geq 30 \cdot 0 \mathrm{~kg} / \mathrm{m}^{2}$ ) and $9 \%$ had grade 2 or 3 obesity (BMI $\geq 35 \cdot 0 \mathrm{~kg} / \mathrm{m}^{2}$ ); (ii) for women, $43 \%$ were underweight/normal weight, $31 \%$ were overweight, $26 \%$ were obese and $11 \%$ had grade 2 or 3 obesity. Men had higher mean BMI than women, although the distributions for both sexes were skewed to the right so that the proportion of women with very high BMI was similar to that of men.

The age-specific distributions of BMI for men and women (Figs 1(a) and 2(a)) show a clear shift in BMI with increasing age, with the $<20$ and 20-29 year age distributions (leftward peaks) clearly separated from the 40 year and older age groups (rightward peaks). The distributions of BMI differed by race ethnicity (Figs 1(b) and 2(b)), with Asians having the lowest BMI and blacks having more donors in the rightward tail of the distribution, particularly among women. Finally, unadjusted BMI distributions differed by educational attainment (data not shown). In men, those with a high school or lower education had a higher proportion of lower BMI while those with some college and college degrees had similar distributions. In women, the distributions of those with high school or lower education and those with college educations were similar, while women with some college had a higher proportion of obesity.

The crude prevalence of obesity was $25 \cdot 1 \%$ among all donors, $25 \cdot 7 \%$ in men and $24 \cdot 4 \%$ among women. We calculated the gender/age/race-standardized obesity prevalences for comparison with those reported by 

Table 1 Prevalence of obesity (BMI $\geq 30 \cdot 0 \mathrm{~kg} / \mathrm{m}^{2}$ ) by sex, donor demographics and other characteristics, and unadjusted/adjusted odds ratios and $95 \%$ confidence intervals, among US blood
donors, Retrovirus Epidemiology in Donors Study II (REDS-II), 2007-2008

\begin{tabular}{|c|c|c|c|c|c|c|c|c|c|c|c|c|}
\hline \multirow[b]{2}{*}{ Variable } & \multicolumn{6}{|c|}{ Men } & \multicolumn{6}{|c|}{ Women } \\
\hline & $n$ & $\%$ Obese & Unadjusted OR & $95 \% \mathrm{Cl}$ & Adjusted OR & $95 \% \mathrm{Cl}$ & $n$ & $\%$ Obese & Unadjusted OR & $95 \% \mathrm{Cl}$ & Adjusted OR & $95 \% \mathrm{Cl}$ \\
\hline Total donors & 506406 & $25 \cdot 7$ & & & & & 536411 & $24 \cdot 4$ & & & & \\
\hline \multicolumn{13}{|l|}{ Age (years) } \\
\hline$<20$ & 104039 & $13 \cdot 0$ & 0.55 & $0.54,0.56$ & 0.44 & $0.42,0.45$ & 114096 & $11 \cdot 3$ & 0.47 & $0.46,0.48$ & 0.34 & $0.33,0.35$ \\
\hline $20-29$ & 77787 & $21 \cdot 4$ & $1 \cdot 00$ & & $1 \cdot 00$ & & 94857 & $21 \cdot 3$ & $1 \cdot 00$ & & 1.00 & \\
\hline $30-39$ & 70712 & $30 \cdot 5$ & $1 \cdot 61$ & $1 \cdot 58,1 \cdot 65$ & $1 \cdot 83$ & $1 \cdot 79,1 \cdot 88$ & 78620 & $30 \cdot 7$ & $1 \cdot 64$ & $1 \cdot 60,1 \cdot 67$ & $1 \cdot 81$ & $1 \cdot 77,1 \cdot 86$ \\
\hline $40-49$ & 101607 & $32 \cdot 2$ & $1 \cdot 75$ & $1 \cdot 71,1 \cdot 78$ & 1.94 & $1 \cdot 89,1.98$ & 107737 & $29 \cdot 2$ & 1.52 & $1 \cdot 49,1 \cdot 55$ & $1 \cdot 67$ & $1 \cdot 63,1 \cdot 71$ \\
\hline $50-59$ & 94428 & $31 \cdot 7$ & $1 \cdot 71$ & $1 \cdot 67,1 \cdot 75$ & 1.92 & $1 \cdot 88,1.97$ & 93588 & $30 \cdot 9$ & $1 \cdot 65$ & $1 \cdot 62,1 \cdot 69$ & 1.81 & $1 \cdot 77,1 \cdot 86$ \\
\hline $60-69$ & 43758 & $29 \cdot 7$ & $1 \cdot 56$ & $1 \cdot 52,1 \cdot 60$ & $1 \cdot 73$ & $1 \cdot 69,1 \cdot 78$ & 37330 & $29 \cdot 7$ & 1.56 & $1 \cdot 52,1 \cdot 60$ & $1 \cdot 66$ & $1 \cdot 61,1 \cdot 71$ \\
\hline $70+$ & 14075 & $21 \cdot 4$ & $1 \cdot 00$ & $0.96,1.05$ & $1 \cdot 06$ & $1 \cdot 01,1 \cdot 11$ & 10183 & $23 \cdot 5$ & $1 \cdot 14$ & $1 \cdot 08,1 \cdot 19$ & $1 \cdot 11$ & $1 \cdot 06,1 \cdot 17$ \\
\hline \multicolumn{13}{|l|}{ Race/ethnicity } \\
\hline White & 432971 & $25 \cdot 8$ & $1 \cdot 00$ & & $1 \cdot 00$ & & 454588 & $23 \cdot 8$ & $1 \cdot 00$ & & 1.00 & \\
\hline Black & 27005 & $32 \cdot 6$ & $1 \cdot 39$ & $1 \cdot 36,1 \cdot 43$ & $1 \cdot 57$ & $1 \cdot 53,1 \cdot 62$ & 35059 & $39 \cdot 0$ & $2 \cdot 05$ & $2 \cdot 01,2 \cdot 10$ & $2 \cdot 35$ & $2 \cdot 29,2 \cdot 41$ \\
\hline Hispanic & 19760 & $26 \cdot 6$ & $1 \cdot 04$ & $1 \cdot 01,1 \cdot 08$ & $1 \cdot 47$ & $1 \cdot 42,1 \cdot 52$ & 22269 & $24 \cdot 4$ & 1.03 & $1 \cdot 00,1 \cdot 07$ & 1.49 & $1 \cdot 44,1.54$ \\
\hline Asian & 14518 & $11 \cdot 4$ & $0 \cdot 37$ & $0.35,0.39$ & 0.59 & $0.56,0.63$ & 11989 & $9 \cdot 1$ & 0.32 & $0.30,0.34$ & 0.54 & $0.51,0.58$ \\
\hline Other & 9362 & $24 \cdot 1$ & 0.91 & $0.87,0.96$ & $1 \cdot 25$ & $1 \cdot 19,1 \cdot 32$ & 10194 & $23 \cdot 8$ & 1.00 & $0.96,1.05$ & $1 \cdot 42$ & $1 \cdot 36,1.50$ \\
\hline \multicolumn{13}{|l|}{ Education } \\
\hline$\leq$ High school & 164662 & $22 \cdot 7$ & $1 \cdot 00$ & & $1 \cdot 00$ & & 173299 & $22 \cdot 1$ & $1 \cdot 00$ & & 1.00 & \\
\hline Some college & 143208 & $31 \cdot 8$ & 1.59 & $1 \cdot 56,1 \cdot 62$ & 0.93 & $0.91,0.95$ & 178771 & $30 \cdot 1$ & 1.52 & $1 \cdot 50,1 \cdot 54$ & $0 \cdot 85$ & $0 \cdot 83,0.86$ \\
\hline$\geq$ College & 192023 & $23 \cdot 8$ & 1.06 & $1 \cdot 04,1 \cdot 08$ & 0.56 & $0.55,0.57$ & 178962 & $21 \cdot 2$ & 0.95 & $0.93,0.96$ & 0.48 & $0.47,0.49$ \\
\hline \multicolumn{13}{|c|}{ Number of pregnancies } \\
\hline Nulligravida & & & & & & & 235838 & $18 \cdot 2$ & $1 \cdot 00$ & & $1 \cdot 00$ & \\
\hline One & & & & & & & 56185 & $30 \cdot 3$ & 1.95 & $1.91,1.99$ & 1.09 & $1 \cdot 06,1 \cdot 11$ \\
\hline Two & & & & & & & 99951 & $28 \cdot 5$ & $1 \cdot 79$ & $1 \cdot 76,1 \cdot 82$ & 0.90 & $0.88,0.92$ \\
\hline Three & & & & & & & 67321 & $29 \cdot 3$ & $1 \cdot 86$ & $1 \cdot 82,1 \cdot 90$ & 0.91 & $0.88,0.93$ \\
\hline Four & & & & & & & 31886 & $30 \cdot 0$ & 1.92 & $1 \cdot 87,1 \cdot 98$ & 0.93 & $0.90,0.96$ \\
\hline Five & & & & & & & 13204 & $30 \cdot 8$ & $2 \cdot 00$ & $1.93,2.08$ & 0.95 & $0.92,1.00$ \\
\hline Six or more & & & & & & & 9146 & $32 \cdot 1$ & $2 \cdot 12$ & $2 \cdot 03,2 \cdot 22$ & 1.03 & $0.98,1.08$ \\
\hline \multicolumn{13}{|l|}{ Birthplace } \\
\hline Not in USA & 25784 & $19 \cdot 1$ & $1 \cdot 00$ & & $1 \cdot 00$ & & 23885 & $17 \cdot 9$ & $1 \cdot 00$ & & $1 \cdot 00$ & \\
\hline USA & 479458 & $26 \cdot 1$ & $1 \cdot 49$ & $1 \cdot 45,1 \cdot 54$ & $1 \cdot 38$ & $1 \cdot 33,1 \cdot 43$ & 511379 & $24 \cdot 7$ & 1.51 & $1 \cdot 46,1 \cdot 56$ & 1.45 & $1 \cdot 40,1 \cdot 50$ \\
\hline \multicolumn{13}{|c|}{ State of blood donation } \\
\hline MA/CT/VT/ME* & 164258 & $24 \cdot 6$ & $1 \cdot 00$ & & 1.00 & & 169637 & $22 \cdot 3$ & 1.00 & & 1.00 & \\
\hline Pennsylvania & 61821 & $28 \cdot 3$ & $1 \cdot 21$ & $1 \cdot 18,1 \cdot 23$ & $1 \cdot 08$ & $1 \cdot 06,1 \cdot 11$ & 60051 & $27 \cdot 1$ & $1 \cdot 30$ & $1 \cdot 27,1 \cdot 33$ & $1 \cdot 14$ & $1 \cdot 11,1 \cdot 16$ \\
\hline Georgia & 124168 & $27 \cdot 2$ & $1 \cdot 14$ & $1 \cdot 13,1 \cdot 16$ & $1 \cdot 10$ & $1 \cdot 08,1 \cdot 12$ & 144113 & $26 \cdot 4$ & $1 \cdot 25$ & $1 \cdot 23,1 \cdot 27$ & 1.09 & $1 \cdot 07,1 \cdot 11$ \\
\hline Ohio & 37924 & $26 \cdot 4$ & $1 \cdot 10$ & $1 \cdot 07,1 \cdot 13$ & $1 \cdot 07$ & $1.04,1.09$ & 42271 & $25 \cdot 8$ & $1 \cdot 21$ & $1 \cdot 18,1 \cdot 24$ & $1 \cdot 13$ & $1 \cdot 10,1 \cdot 16$ \\
\hline Wisconsin & 64593 & $26 \cdot 6$ & $1 \cdot 11$ & $1 \cdot 09,1 \cdot 13$ & $1 \cdot 05$ & $1 \cdot 02,1 \cdot 07$ & 68854 & $25 \cdot 5$ & $1 \cdot 20$ & $1 \cdot 17,1 \cdot 22$ & $1 \cdot 11$ & $1 \cdot 09,1 \cdot 14$ \\
\hline California & 53642 & $21 \cdot 1$ & $0 \cdot 82$ & $0.80,0.84$ & $0 \cdot 82$ & $0.79,0.84$ & 51485 & $20 \cdot 3$ & $0 \cdot 89$ & $0.87,0.91$ & 0.87 & $0.87,0.91$ \\
\hline \multicolumn{13}{|l|}{ Donor status } \\
\hline Repeat donor & 300140 & $28 \cdot 2$ & $1 \cdot 00$ & & 1.00 & & 300263 & $27 \cdot 1$ & 1.00 & & 1.00 & \\
\hline First-time donor & 203950 & $22 \cdot 0$ & 0.72 & $0.71,0.73$ & 0.98 & $0 \cdot 97,1 \cdot 00$ & 233661 & $21 \cdot 0$ & $0 \cdot 72$ & $0 \cdot 71,0.72$ & 0.93 & $0.92,0.94$ \\
\hline \multicolumn{13}{|l|}{ Donation type } \\
\hline Whole blood & 443059 & $25 \cdot 0$ & $1 \cdot 00$ & & $1 \cdot 00$ & & 519498 & $24 \cdot 0$ & 1.00 & & 1.00 & \\
\hline Double red cell & 50101 & $30 \cdot 8$ & $1 \cdot 33$ & $1 \cdot 31,1 \cdot 36$ & $1 \cdot 39$ & $1 \cdot 36,1 \cdot 42$ & 5659 & $48 \cdot 4$ & $2 \cdot 97$ & $2 \cdot 82,3 \cdot 13$ & $2 \cdot 78$ & $2 \cdot 63,2 \cdot 94$ \\
\hline Platelet apheresis & 13246 & $30 \cdot 7$ & $1 \cdot 33$ & $1 \cdot 28,1 \cdot 38$ & $1 \cdot 17$ & $1 \cdot 13,1 \cdot 22$ & 11254 & $31 \cdot 5$ & $1 \cdot 46$ & $1 \cdot 40,1 \cdot 52$ & 1.29 & $1 \cdot 24,1 \cdot 35$ \\
\hline \multicolumn{13}{|c|}{ Donor's transfusion history } \\
\hline Never transfused & 465112 & $25 \cdot 4$ & $1 \cdot 00$ & & $1 \cdot 00$ & & 497056 & $23 \cdot 9$ & $1 \cdot 00$ & & $1 \cdot 00$ & \\
\hline Ever transfused & 14464 & $31 \cdot 0$ & $1 \cdot 32$ & $1 \cdot 27,1 \cdot 37$ & $1 \cdot 11$ & $1 \cdot 07,1 \cdot 15$ & 22147 & $32 \cdot 2$ & $1 \cdot 51$ & $1 \cdot 47,1 \cdot 56$ & $1 \cdot 18$ & $1 \cdot 14,1 \cdot 21$ \\
\hline
\end{tabular}



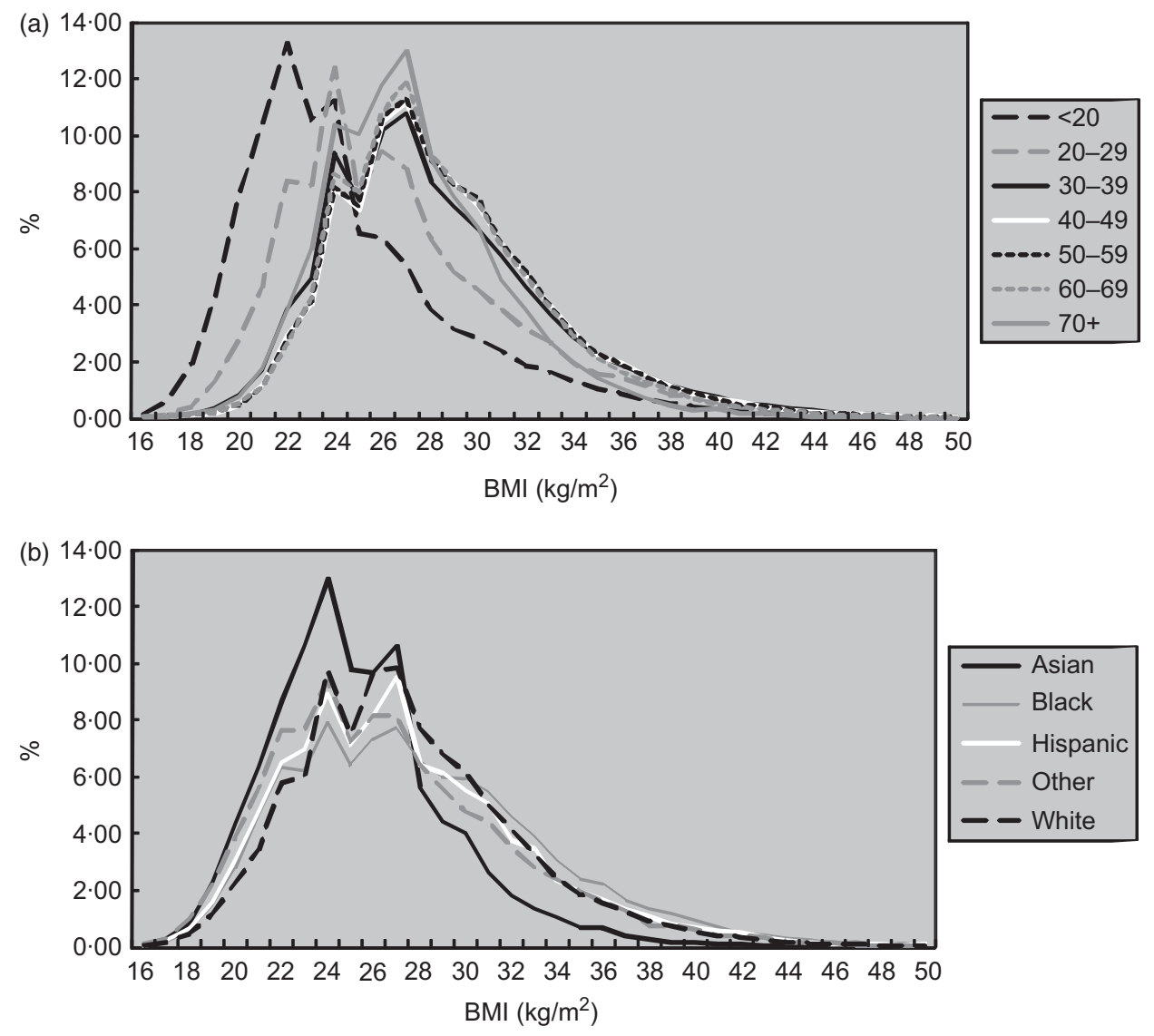

Fig. 1 Distribution of BMI $\left(\mathrm{kg} / \mathrm{m}^{2}\right.$ ) according to (a) age (years) and (b) race/ethnicity among male US blood donors ( $n$ 506 406), Retrovirus Epidemiology in Donors Study II (REDS-II), 2007-2008

NHANES. Among male blood donors, the standardized prevalence of obesity was $29 \cdot 6 \%$ (all ages), $26 \cdot 9 \%$ (age 20-39 years), $33 \cdot 0 \%$ (age $40-59$ years) and $28 \cdot 3 \%$ (age 60 years plus), while among male NHANES participants it was $32 \cdot 2 \%$ (all ages), $27 \cdot 5 \%$ (age $20-39$ years), $34 \cdot 3 \%$ (age $40-59$ years) and $37 \cdot 1 \%$ (age 60 years plus). Among female donors, the standardized prevalence of obesity was $29 \cdot 5 \%$ (all ages), $27 \cdot 3 \%$ (age 20-39 years), 31.7\% (age 40-59 years) and $29 \cdot 6 \%$ (age 60 years plus), while among female NHANES participants it was $35.5 \%$ (all ages), $34 \cdot 0 \%$ (age $20-39$ years), $38 \cdot 2 \%$ (age $40-59$ years) and $33.6 \%$ (age 60 years plus). Thus male donors had obesity prevalence similar to that of NHANES at younger ages, while older male and all female donors had lower obesity prevalence than NHANES participants.

Table 1 shows the prevalence of obesity (BMI $\geq$ $30 \cdot 0 \mathrm{~kg} / \mathrm{m}^{2}$ ) according to demographic and other characteristics of the donors, as well as aOR for the association between obesity and these characteristics. The prevalence of obesity rose with age, reaching a maximum in the 40-49 year age group for men and 50-59 year age group for women, and declining thereafter. Male and female donors of black and Hispanic race/ethnicity higher odds of obesity than those of white race/ethnicity, and black women had more than twice the adjusted odds of obesity compared with white women. Asian donors had only half the adjusted odds of obesity compared with whites. The unadjusted prevalence of obesity was highest in donors with some college education, but controlling for age in the multivariable analysis showed aOR consistent with an inverse association of obesity with education. The association of obesity with increasing number of pregnancies among women showed a more complex relationship, with one pregnancy increasing the aOR by about $10 \%$ and the next few pregnancies lowering the aOR, while for six or more pregnancies the aOR was no different from unity.

Donors born in the USA had increased odds of obesity compared with their foreign-born counterparts. There were also moderate regional differences in the prevalence of obesity. Donors at the four centres in Pennsylvania, Georgia, Ohio and Wisconsin had about 5-15\% higher adjusted odds of obesity than their counterparts in New England, while donors in California had more than $10 \%$ lower adjusted odds compared with their New England counterparts.

Blood donation characteristics were also associated with the prevalence of obesity. Male and female repeat donors had a higher prevalence of obesity, although differences were minimal after adjustment for age and 

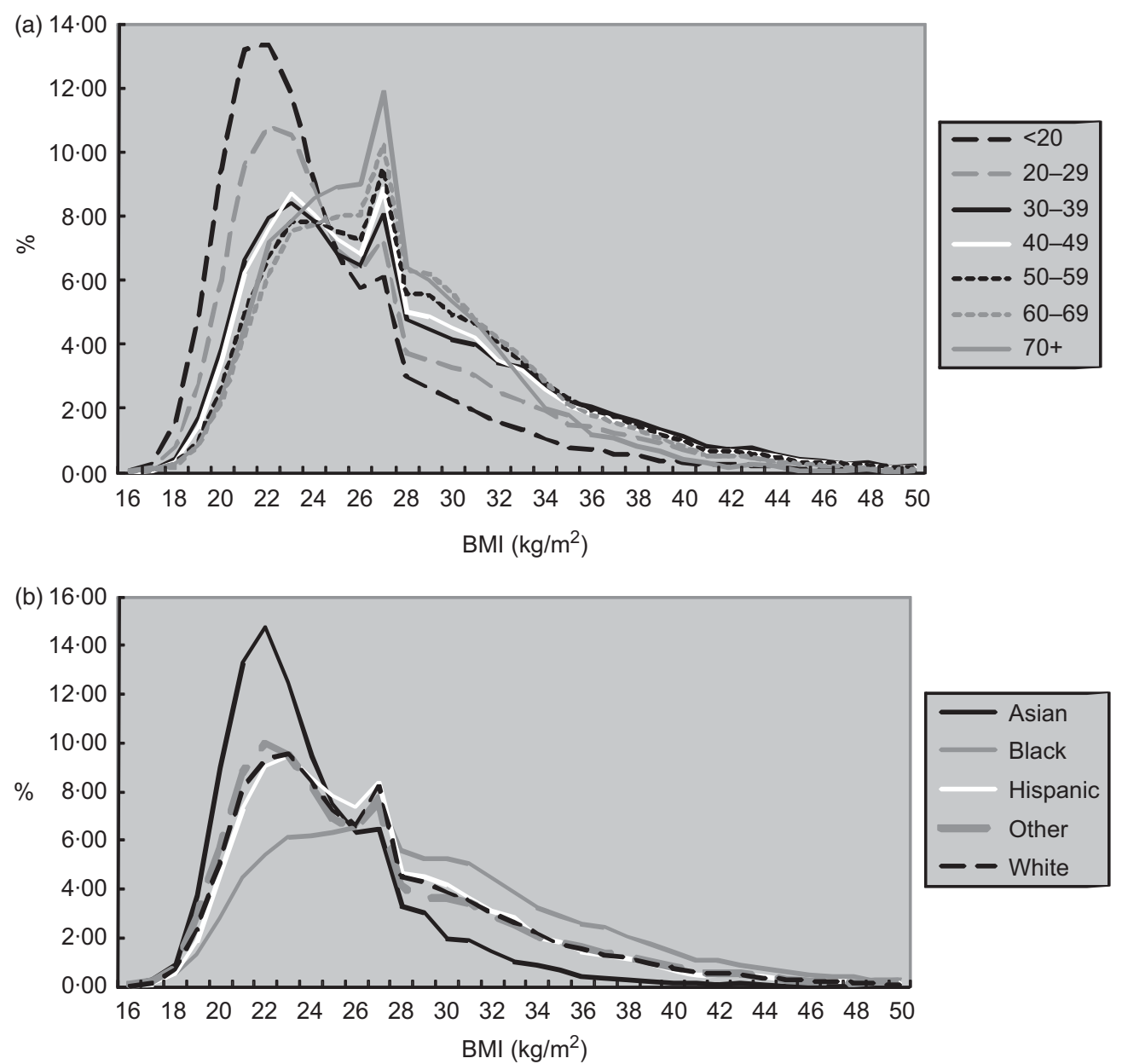

Fig. 2 Distribution of BMI $\left(\mathrm{kg} / \mathrm{m}^{2}\right)$ according to (a) age (years) and (b) race/ethnicity among female US blood donors ( $n$ 536 411$)$, Retrovirus Epidemiology in Donors Study II (REDS-II), 2007-2008

other covariates (Table 1). Platelet apheresis donors had a slightly higher prevalence of obesity. Double red cell collections had a significantly higher prevalence of obesity, especially for women, consistent with minimum weight requirements for this type of donation. Finally, donors who have ever received a blood transfusion had a higher prevalence and odds of obesity compared with never transfused donors.

\section{Discussion}

These data, based on more than one million US blood donors, show a prevalence of obesity that is modestly lower than in the US general population, but still much higher than public health targets of $15 \%$ obesity among adults ${ }^{(11)}$. We also found associations with age, race/ethnicity and education similar to those found in NHANES. Taken together, the data support the concept that the blood centre may be a useful venue for monitoring population trends in obesity and, potentially, introducing interventions towards the maintenance of healthy BMI.
Compared with age- and sex-specific NHANES data ${ }^{(4)}$, blood donors had relative prevalences of obesity that were modestly lower in all age and sex subgroups, except for men aged 20-59 years who had obesity prevalence comparable to NHANES. These differences are likely due to selection bias operating on donors, including selection by the blood banks for healthy individuals and selfselection for donation by individuals with higher educational achievement, which is related to lower rates of obesity $^{(12)}$.

The distribution of BMI in both sexes showed a strong dependence on age. Most of this effect was likely due to biological factors, namely reduced metabolic demands in older persons coupled with a continued high caloric diet in the USA. However it is also conceivable that lower BMI in the youngest age groups represents a secular trend towards reduced BMI, as previously suggested ${ }^{(13,14)}$. Thus, recent public health educational efforts directed towards the young or changes in lifestyle may become durable as these groups age. Because of the large size and ongoing nature of the available data sets, prospectively gathered blood centre data could provide an excellent 
opportunity for dissecting the effects of biological ageing and secular trends in the prevalence of obesity.

Projections of future trends in obesity have substantial implications for public health policy and expenditures related to CVD and other adverse outcomes of obesity. Olshansky et al. were the first to postulate a potential decline in US life expectancy during the 21st century due to obesity, despite gains made in the reduction of other cardiovascular risk factors ${ }^{(15)}$. For example, gains in life expectancy related to decreased prevalence of cigarette smoking, hypertension and dietary fat intake may be counterbalanced by an increasing prevalence of obesity ${ }^{(1,16)}$. Obesity may also be related to increased incidence of pancreatic and prostate cancer ${ }^{(17,18)}$, decreased health-related quality of life ${ }^{(19)}$, and increased mortality and decreased healthy survival in the elderly ${ }^{(3,20)}$. On a positive note, some authors have suggested that the epidemic of increasing obesity from 1970 to 2000 has begun to level off in the last decade, but additional data are needed to confirm this ${ }^{(4,21)}$.

We also showed strong associations between obesity and race/ethnicity, country of birth and gravidity. Donors of black race/ethnicity, especially women, were more likely to have higher BMI and obesity prevalence, as observed in NHANES ${ }^{(4)}$. However those authors caution that differences in BMI between race/ethnic groups do not directly correlate with adiposity since muscle to fat ratios may differ by ancestry. Likewise, different race/ ethnic groups may have difference risks for CVD or other adverse outcomes of obesity for any given BMI. As other authors have noted particularly among Hispanics, we observed that foreign-born donors had lower prevalence of obesity than US-born donors, consistent with the observation that immigrants have healthier diets than US-born donors ${ }^{(22)}$. Although women with a previous pregnancy were more likely to be obese than nulliparous women, we did not see a strong relationship between obesity and higher gravidity values, consistent with a previous report based upon NHANES data ${ }^{(23)}$.

Whereas obesity was more prevalent in those with some college education than in those with high school or lower and college or higher education, the multivariate analysis showed an inverse relation with educational attainment. Higher socio-economic status is generally inversely associated with obesity in high-income countries but directly associated with obesity in lower-income countries $^{(24)}$. However, data in the USA support a weakening of the inverse association between socio-economic status and obesity in recent decades, particularly among blacks ${ }^{(25)}$. Our data also showed regional differences in obesity prevalence within the USA that are similar to those reported elsewhere, and likely represent regional differences in diet and exercise ${ }^{(5)}$.

We showed marked differences in obesity prevalence according to the type of blood donation made by the donor, in order of increasing obesity prevalence: whole blood donors; platelet apheresis donors; and double red cell donors. Compared with unadjusted OR, the aOR accounting for confounding by covariates showed some reduction for platelet donors but not for double red cell donors. This indicates that selection of donors for specific donation procedures according to body weight results in enrichment of obese donors. Whereas specific weight criteria are applied to double red cell donors in order to guarantee minimum blood volume, there are not overt weight criteria for platelet donation, although donors may be selected according to previous platelet yield, which in turn may be related to blood volume and body weight. On the other hand, the higher prevalence of obesity in repeat donors was attenuated in the multivariate analysis, suggesting confounding by age or other variables as well as selection for heavier (larger blood volume) repeat donors who can better maintain iron stores with repeated phlebotomy. We were surprised to find an increased prevalence of obesity among donors with a history of receiving a blood transfusion, with $\mathrm{aOR}=1 \cdot 11$ (men) and $1 \cdot 18$ (women) after multivariable adjustment. Perhaps illnesses associated with obesity are also associated with an increased likelihood of blood transfusion, even among generally healthy blood donors. Finally, blood bankers should be aware of the high prevalence of obesity among female donors selected for automated collections, including the possibility that formulas based on height and weight may overestimate blood volume in obese donors. In order to prevent hypotensive reactions that are more frequent in donors with lower blood volume, such formulas may need to be adapted to account for adiposity $v$. lean body mass.

Strengths of the study include its very large population size, uniform collection of height and weight data as well as other covariates, and the ongoing nature of data collection in the blood centre setting. Limitations include the use of self-report instead of direct measurement of height and weight, because underestimation of weight and overestimation of height by respondents may have led to underestimation of BMI. A Swiss study found that selfreported height and weight underestimates BMI by $0.8 \mathrm{~kg} /$ $\mathrm{m}^{2}$ in men and $1.0 \mathrm{~kg} / \mathrm{m}^{2}$ in women, and proposed an algorithm for transforming self-reported data ${ }^{(26)}$. A similar approach could be used to standardize US self-reported blood donor data to measured height and weight in a subsample of donors. Another limitation is the exclusion of individuals with very low body weight from blood donation and hence from participation in our data. Only 2326 $(<0 \cdot 3 \%)$ prospective donors were deferred for low body weight during our study period, although more persons may have self-deferred and not attempted to donate. Finally, a 'healthy donor' effect, namely selection bias of healthy individuals for blood donation, may operate in our data ${ }^{(12)}$. The exclusion for low weight would imply overestimation of BMI, whereas the 'healthy donor effect' would tend to exclude extremes of BMI. Nevertheless our data are comparable to albeit slightly lower than NHANES BMI data, suggesting that the extent of such biases is relatively modest. 


\section{Conclusions}

We found a moderately high prevalence of obesity among otherwise healthy US blood donors, with demographic associations comparable to those seen in populationbased studies. Because of the ongoing nature of data collection, the blood centre may be a useful venue for measuring period and cohort effects in BMI in obesity prevalence in the USA and other countries. As some blood centres move towards measurement of cholesterol and glycosylated $\mathrm{Hb}$ as a service to donors, the combination of these indices with BMI could lead to useful health education measures and even interventions to induce health-conscious blood donors to maintain healthier diet and lifestyles.

\section{Acknowledgements}

This work was supported by the National Heart, Lung, and Blood Institute (NHLBI contracts N01-HB-47168, -47169, $-47170,-47171,-47172,-47174,-47175$ and -57181$)$. The authors have no conflicts of interest or other financial involvement to declare. E.L.M. designed the study, coordinated data analysis and wrote the manuscript. K.S. performed data analysis and reviewed the manuscript. D.J.W. provided statistical consultation and reviewed the manuscript. R.C. collected data and reviewed the manuscript. J.R. collected data and reviewed the manuscript. R.S. collected data and reviewed the manuscript. M.P.B. collected data and reviewed the manuscript. The authors are grateful to the staff of the participating blood centres, without whose help this research could not have been completed. They also thank Ms Susan Yuen for assistance in manuscript preparation.

\section{References}

1. Stewart ST, Cutler DM \& Rosen AB (2009) Forecasting the effects of obesity and smoking on US life expectancy. $N$ Engl J Med 361, 2252-2260.

2. Mehta NK \& Chang VW (2009) Mortality attributable to obesity among middle-aged adults in the United States. Demography 46, 851-872.

3. Sun Q, Townsend MK, Okereke OI et al. (2009) Adiposity and weight change in mid-life in relation to healthy survival after age 70 in women: prospective cohort study. BMJ339, b3796.

4. Flegal KM, Carroll MD, Ogden CL et al. (2010) Prevalence and trends in obesity among US adults, 1999-2008. JAMA 303, 235-241.

5. Gregg E, Kirtland K, Cadwell B et al. (2009) Estimated county-level prevalence of diabetes and obesity United States, 2007. MMWR Morb Mortal Wkly Rep 58, 1259-1263.

6. Petersen LR \& Doll LS (1991) Human immunodeficiency virus type 1-infected blood donors: epidemiologic, laboratory, and donation characteristics. The HIV Blood Donor Study Group. Transfusion 31, 698-703.
7. Busch MP, Wright DJ, Custer B et al. (2006) West Nile virus infections projected from blood donor screening data, United States, 2003. Emerg Infect Dis 12, 395-402.

8. American Association of Blood Banks (2011) Standards for Blood Banks and Transfusion Services, 27th ed., p. 56. Bethesda, MD: AABB

9. Wiltbank TB, Giordano GF, Kamel H et al. (2008) Faint and prefaint reactions in whole-blood donors: an analysis of predonation measurements and their predictive value. Transfusion 48, 1799-1808.

10. Rios JA, Fang J, Tu Y et al. (2010) The potential impact of selective donor deferrals based on estimated blood volume on vasovagal reactions and donor deferral rates. Transfusion 50, 1265-1275.

11. US Department of Health and Human Services (2000) Healthy People 2010: Understanding and Improving Health, 2nd ed. Washington, DC: US Government Printing Office.

12. Atsma F \& de Vegt F (2011) The healthy donor effect: a matter of selection bias and confounding. Transfusion $\mathbf{5 1}$, 1883-1885.

13. Wang YC, Colditz GA \& Kuntz KM (2007) Forecasting the obesity epidemic in the aging US population. Obesity (Silver Spring) 15, 2855-2865.

14. Reither EN, Hauser RM \& Yang Y (2009) Do birth cohorts matter? Age-period-cohort analyses of the obesity epidemic in the United States. Soc Sci Med 69, 1439-1448.

15. Olshansky SJ, Passaro DJ, Hershow RC et al. (2005) A potential decline in life expectancy in the United States in the 21st century. $N$ Engl J Med 352, 1138-1145.

16. Arnett DK, McGovern PG, Jacobs DR Jr et al. (2002) Fifteen-year trends in cardiovascular risk factors (1980-1982 through 1995-1997): the Minnesota Heart Survey. Am J Epidemiol 156, 929-935.

17. Silverman DT, Hoover RN, Brown LM et al. (2003) Why do Black Americans have a higher risk of pancreatic cancer than White Americans? Epidemiology 14, 45-54.

18. Fesinmeyer MD, Gulati R, Zeliadt S et al. (2009) Effect of population trends in body mass index on prostate cancer incidence and mortality in the United States. Cancer Epidemiol Biomarkers Prev 18, 808-815.

19. Ford ES, Moriarty DG, Zack MM et al. (2001) Self-reported body mass index and health-related quality of life: findings from the Behavioral Risk Factor Surveillance System. Obes Res 9, 21-31.

20. Corrada MM, Kawas CH, Mozaffar F et al. (2006) Association of body mass index and weight change with all-cause mortality in the elderly. Am J Epidemiol 163, 938-949.

21. Basu A (2010) Forecasting distribution of body mass index in the United States: is there more room for growth? Med Decis Making 30, E1-E11.

22. Park J, Myers D, Kao D et al. (2009) Immigrant obesity and unhealthy assimilation: alternative estimates of convergence or divergence, 1995-2005. Soc Sci Med 69, $1625-1633$.

23. Lee SK, Sobal J, Frongillo EA et al. (2005) Parity and body weight in the United States: differences by race and size of place of residence. Obes Res 13, 1263-1269.

24. McLaren L (2007) Socioeconomic status and obesity. Epidemiol Rev 29, 29-48.

25. Zhang Q \& Wang Y (2004) Trends in the association between obesity and socioeconomic status in US adults: 1971 to 2000. Obes Res 12, 1622-1632.

26. Faeh D, Braun J \& Bopp M (2009) Underestimation of obesity prevalence in Switzerland: comparison of two methods for correction of self-report. Swiss Med Wkly 139, 752-756. 


\section{Appendix}

The Retrovirus Epidemiology Donor Study II (REDS-II Study Group) is the responsibility of the following persons: R. Cable, J. Rios and R. Benjamin (American Red Cross Blood Services, New England Region); J.D. Roback (American Red Cross Blood Services, Southern Region/ Department of Pathology and Laboratory Medicine, Emory University School of Medicine); R.A. Sacher, S.L. Wilkinson and P.M. Carey (Hoxworth Blood Center,
University of Cincinnati Academic Health Center); E.L. Murphy, B. Custer and N. Hirschler (Blood Centers of the Pacific and University of California San Francisco); D. Triulzi, R. Kakaiya and J. Kiss (The Institute for Transfusion Medicine); J. Gottschall and A. Mast (Blood Center of Wisconsin); J. Schulman and M. King (Coordinating Center: Westat, Inc.); M.P. Busch and P. Norris (Central Laboratory: Blood Systems Research Institute); and G.J. Nemo (National Heart, Lung and Blood Institute, $\mathrm{NIH})$. 